\title{
16th Annual Conference of the Society on Neuroimmune Pharmacology
}

\author{
Guy A. Cabral $\cdot$ Thomas J. Rogers
}

Received: 1 February 2010 /Accepted: 3 February 2010/Published online: 23 February 2010

(C) Springer Science+Business Media, LLC 2010

\section{Welcome to the 16th Annual Conference of the Society on NeuroImmune Pharmacology}

We are pleased to publish the abstracts from this Conference in the Journal of Neuroimmune Pharmacology. We are most pleased that Springer has agreed to provide these abstracts in open access; this is the first time the abstracts from our Conference will be published in their entirety. The Society on NeuroImmune Pharmacology recognizes the continued support of Dr. Howard Gendelman and Robin Taylor, our chief and managing editors, and Ann Avouris, Springer US, in seeing this process to fruition.

This year's conference-April 14-17, 2010, at the Manhattan Beach Marriott Hotel, Manhattan Beach, CA, USA-will maintain a focus on drugs of abuse in modulating neuroimmune processes and on HIV infection. A major objective of the conference is to support young investigators. The "highlight" event will be the Young Investigator Poster Session followed by a "Meet the Mentors" buffet at which young investigators will interact with senior investigators from academia, the National Institutes of Health, and industry to discuss career opportunities. In addition, a General Poster Session will be held. Abstracts of the 16th

G. A. Cabral

Department of Microbiology and Immunology,

School of Medicine, Virginia Commonwealth University,

Richmond, VA, USA

T. J. Rogers $(\bowtie)$

Fels Institute for Cancer Research and Molecular Biology,

Center for Substance Abuse Research, Center for Inflammation,

Translational and Clinical Lung Research,

Temple University School of Medicine,

Philadelphia, PA, USA

e-mail: rogerst@temple.edu
Annual Meeting of the Society will be published in the Journal of Neuroimmune Pharmacology.

Two Plenary Lectures will be presented. The first will be by Stuart Lipton, M.D., Ph.D., Scientific Director of the Burnham Center for Neuroscience, Aging, and Stem Cell Research. The second Plenary Lecture will be presented by Vincenzo Di Marzo, from the Istituto di Chimica Biomolecolare Nazionale delle Ricerche, Pozzuoli, Italy. Dr. DiMarzo will provide a general introduction on endocannabinoids and related lipid mediators and their emerging role in neuroinflammatory disorders. There also will be four symposia on HIV-related and Drug Abuse-related topics: "Effects of HIV-1 in Promoting Alcohol Addiction and Mechanisms of Associated Neurodegeneration"; "Opiates, Other Drugs of Abuse and Co-Infections"; "Epigenomic Regulation in Neuroscience and HIV Infection"; and a Special Thursday Evening Symposium hosted by the UCLA Center for AIDS Research and the UCLA AIDS Institute entitled "HIV and Host Immunity in the Design of Novel Therapeutic Approaches." This Special Evening Symposium will address interventional therapies and translational research related to HIV and its pathogenesis. In addition, there will be a symposium that will address the issue of tobacco and nicotine entitled "The News About Tobacco Smoke Is Worse than You Think" and a symposium on "Neuroimmunopharmacology and the Cannabinoid System." The major symposium lecture for the symposium on tobacco and nicotine will be presented by Nancy Kerkvliet, Ph.D., Professor of Environmental and Molecular Toxicology at Oregon State University. A highlight symposium will address "Nanomedicine and Drug Delivery." The symposium lecture for this session will be presented by Andre Nel, Ph.D., Chief, Division of Nanomedicine at the UCLA Geffen School of Medicine.

There will be a Young Investigator's Symposium sponsored by the SNIP Young Investigator Travel Award 
(YITA) Committee. The Committee will select as presenters two postdoctoral and two predoctoral speakers from the pool of submitted Young Investigator abstracts. In addition, there will be a Luncheon Technical Workshop sponsored by the National Institute on Drug Abuse and the National Institute on Alcohol Abuse and Alcoholism that will address new initiatives at the National Institutes of Health, Grant Writing, and the Grant Review Process. A final highlight presentation will be the Saturday evening Banquet Lecture that will be given by Patricia Molina, M.D., Ph.D., from the Louisiana State University Health Science Center in New Orleans.

The Manhattan Beach Marriott Hotel conference site is conveniently located 3 miles south of Los Angeles International Airport (LAX) and a mile and a half from the village of Manhattan Beach. Manhattan Beach is a funky ocean town with surfing, sunning on the beach, eating in small local restaurants, and walking the sand dunes.
Los Angles boasts an array of things to do-golfing at the hotel on an executive size course (all holes less than 175 yards), touring Hollywood, "beaching it," sitting in the audience for the Jay Leno show, or munching wood-burned pizza at Spagos. The Meetings Committee has left Friday afternoon open to allow conference participants to indulge whatever fantasies they may have regarding the "City of the Angels." One possibility would be to join a group of attendees on a trip to the Getty Museum - one of the great new museums in the country. It is possible to spend the afternoon wandering around the spectacular grounds housing the collections.

We thank the Carol Swarts Emerging Neuroscience Laboratory, University of Nebraska Medical Center; the Society on NeuroImmune Pharmacology; and Springer for their support in publishing this abstract book.

Again, welcome to the 16th Annual Conference of the Society on NeuroImmune Pharmacology. 